\title{
"NEM AQUI NEM LÁ"1: RASTROS DO FEMININO NAS FOTOPERFORMANCES DE ANA MENDIETA
}

\author{
Olga da Costa Lima Wanderley
}

\begin{abstract}
Resumo
Este artigo aborda as questões acionadas pelo trabalho da artista cubana-americana Ana Mendieta, que tem grande parte da sua obra composta por performances elaboradas exclusivamente para a câmera e pelo que a própria artista denominou como earth-body-works. Através das suas estratégias de representação baseadas no desaparecimento do corpo feminino, Mendieta chama a nossa atenção para as violências e apagamentos legitimados por meio do estabelecimento de identidades fixas - étnicas e de gênero - no interior dos discursos hegemônicos de poder. Serão exploradas as noções de performance como instrumento para transmissão de conhecimento e memória cultural, de performatividade como fator constitutivo das categorias de identidade e, ainda, de arquivo, repertório e acontecimento ao vivo no esforço de problematizar como as temáticas do exílio e do feminino, regulares na arte de Mendieta, atingem uma dimensão profundamente política a partir das suas proposições artísticas que integram a fotografia com a arte performática.
\end{abstract}

\section{Palavras-chave}

Ana Mendieta; fotografia; feminilidade; performance; performatividade

\begin{abstract}
This article addresses the questions triggered by the work of the Cuban-American artist Ana Mendieta, who has a large part of her work composed exclusively of camera performances and what she termed earth-body-works. Through her strategies of representation based on the disappearance of the female body, Mendieta draws our attention to the legitimized violence and erasures through the establishment of fixed identities - ethnic and gender - within the hegemonic discourses of power. The notions of performance as an instrument for transmission of knowledge and cultural memory, of performativity as a constitutive factor of the categories of identity, as well as of archive, repertory and live event will be explored in the effort to problematize as the themes of exile and feminine, regular in the art of Mendieta, reach a deeply political dimension based on their artistic propositions that integrate photography with performance art.
\end{abstract}

\section{KeYwORDS}

Ana Mendieta; photography; feminility; performance; performativity

\footnotetext{
1 "Nem aqui nem lá" foi uma expressão utilizada por Jane Blocker para se referir à obra Isla, de Mendieta, conforme veremos ao longo do nosso artigo.
} 


\section{INTRODUÇÃO}

A década de 70 foi permeada por um intenso experimentalismo estético, além de um forte engajamento político no campo das criações artísticas. Reivindicações por diversos direitos e pelas liberdades individuais eram frequentemente expressas por meio de uma multiplicidade de intervenções criativas sobre a paisagem ou sobre o corpo humano. Manifestações como a performance, a bodyart e a landart ganharam espaço como possibilidades de uma arte efêmera e extremamente diversificada, que privilegia o conceito e o gesto criador em detrimento do objeto. Estas linguagens - herdeiras do caráter transgressor presente nas vanguardas europeias do início do século XX - desenvolveram-se por todo o mundo, e tiveram especial destaque no contexto artístico-político norte-americano.

É neste cenário que se inscreve a trajetória da artista cubana-americana Ana Mendieta. Nascida em Havana, em 1948, mudou-se para os Estados Unidos em 1961, junto com sua irmã mais velha, devido às divergências políticas existentes entre sua família e o regime de Fidel Castro. Foi na Universidade de lowa que Mendieta estudou artes plásticas e teve contato - através do Programa Intermedia ${ }^{2}$ - com a enorme efervescência artística dos anos 70. As expressões da arte corporal e arte ambiental inspiraram fortemente seu trabalho e chegaram a ser uma marca das suas criações. Outra influência evidente na vida artística de Mendieta foi a proximidade que veio a ter com o movimento feminista.

Muitas artistas naquele período participaram de maneira ativa das lutas pelos direitos das mulheres e empregaram seus próprios corpos como um material artístico e questionador dos papéis sociais atribuídos ao gênero e da objetificação imposta aos corpos femininos. Mendieta teve seu envolvimento com as reivindicações feministas e utilizou suas obras como forma de escancarar as inúmeras opressões e apagamentos sofridos pelas mulheres, dentro e fora do mundo da arte.

Os aspectos da feminilidade, junto às questões de nacionalidade, exílio e ritos ancestrais das culturas latino-americanas são abordagens recorrentes no extenso número de trabalhos de Mendieta. O corpo em sua obra é quase sempre representado em meio aos elementos da natureza, como terra, fogo, água, plantas e sangue de animais. Ela mesma denominou suas criações como earth-body works ou earth-body sculptures ${ }^{3}$, e declarou:

minha arte é a forma de eu reestabelecer os laços que me unem ao universo. É um retorno à fonte materna. Através das minhas esculturas de terra/ corpo eu me torno uma com a terra... eu me torno uma extensão da natureza e a natureza torna-se uma extensão do meu corpo. Este ato obsessivo de reafirmar meus laços com a terra é realmente a reativação de crenças

\footnotetext{
${ }^{2}$ Inovador programa de pós-graduação, dirigido por Hans Breder, que explorava espaços de integração entre mídias e práticas artísticas diversas.

${ }^{3}$ Grande parte da sua obra foi composta por impressões do próprio corpo sobre a paisagem, em um misto de performance, escultura e arte ambiental - ou earth works.
} 
primitivas... uma força feminina onipresente, a pós-imagem de ser envolvida dentro do útero4.

Tal ligação com a natureza, descrita por Mendieta, contudo, não parece remeter a uma relação essencialista com o feminino ou com os antigos rituais da sua cultura de origem. Veremos que, ao contrário, o desaparecimento e a dissolução do corpo em meio à paisagem podem ser lidos como metáfora para uma recusa em se fixar a qualquer categoria de identidade - seja nacional, étnica ou de gênero. Outro fator relevante em suas escolhas estéticas foi a utilização massiva da fotografia, muitas vezes como único meio de acesso do público às suas obras, problematizando, assim, a noção que alude a uma essência das artes performáticas como acontecimentos primordialmente ao vivo.

Mendieta morreu de forma trágica, em 1985, mesmo ano em que se casou com o escultor minimalista Carl Andre. A artista caiu do seu apartamento, localizado no trigésimo quarto andar de um edifício em Nova York. Andre foi acusado pelo assassinato, mas foi absolvido em seguida, tendo a defesa alegado que Ana cometera suicídio. Em junho de 1992, um grupo feminista realizou um protesto em frente ao Museu Guggenheim, onde estava sendo inaugurada uma exposição que incluía obras de quatro artistas brancos, do sexo masculino - entre eles Carl Andre - e apenas uma artista mulher.

As manifestantes jogaram fotografias de Mendieta sobre as esculturas de Andre e exibiram uma faixa que dizia "Carl Andre está no Guggenheim. Onde está Ana Mendieta?" (Blocker, 1999, p. 1). Segundo Jane Blocker, ao perguntar onde Mendieta está, as mulheres que protestavam queriam realmente salientar onde ela não estava. A pergunta produz performativamente a sua ausência e desse modo questiona as estruturas de poder que conferem visibilidade ou invisibilidade com base na construção discursiva de cor, raça, gênero, religiosidade. Sobre os discursos de poder que cercam o trabalho de Mendieta, Blocker afirma:

embora ela apareça frequentemente em exposições e textos que tentam mapear os territórios desconhecidos da performatividade, feminilidade e latinidade, ela é tão frequentemente ausente deles, para o bem e para o mal. O Mapeamento das margens pode servir apenas para reforçar os centros e, em última análise, o poder daqueles que os ocupam. (Bloker, 1999, p. 21)

Desse modo, nos dedicaremos a investigar as produções discursivas que perpassam o trabalho artístico de Ana Mendieta e frequentemente estabelecem um mapeamento das suas obras - bem como da sua trajetória pessoal - dentro de uma identidade de artista latina, profundamente entrelaçada à dor do seu exílio e à ideia de uma feminilidade exótica. Além disso, veremos como as próprias obras da artista nos oferecem possibilidades de leitura que subvertem sua fixação em tais identidades através do jogo de presença e ausência, inclusive pelo uso do dispositivo fotográfico como um meio para garantir a permanência de ações criadoras compreendidas como essencialmente efêmeras.

${ }_{4}$ Retirado de http://www.tate.org.uk/art/artworks/mendieta-untitledsilueta-series-mexico-t13356/text-summary 


\section{ROTEIROS, LATINIDADE E EXÍLIO}

Diane Taylor (2013) nos fornece meios para compreender a performance como um sistema epistêmico, uma forma de transferir conhecimento, memória e identidade social através de práticas incorporadas, tais como danças, rituais e modos de fazer tradicionais. Ela aponta que o pensamento ocidental introduziu grande ênfase nos documentos e textos como forma de descrição dos dramas sociais, garantindo a certos grupos o privilégio de registrar suas narrativas em detrimento das ações performatizadas por outros atores. Taylor questiona este sistema de conhecimento e argumenta:

se, contudo, formos reorientar os modos como se tem estudado tradicionalmente a memória e a identidade cultural nas Américas (...) para olhar através das lentes de comportamentos performatizados, incorporados, o que saberíamos então que agora não sabemos? De quem seriam as histórias, memórias e lutas que se tornariam visíveis? Que tensões poderiam ser mostradas pelos comportamentos em performance que não seriam reconhecidas nos textos e documentos? (Taylor, 2013, p. 20)

As histórias e tradições culturais tornadas visíveis são legitimadas através de roteiros que a autora descreve a partir da viagem de Colombo às Américas. Os roteiros de descobrimento produzem a relação entre um "nós"- o descobridor, aquele que vê - e um "outro" - o nativo selvagem, aquele que é olhado -, estabelecendo suas posições dentro de um sistema de poder. O nativo tem sua atuação esvaziada ao ser mapeado pelo descobridor - como os ameríndios no exemplo de Taylor, que "apesar de presentes fisicamente são reconhecidos apenas para 'serem desaparecidos' nesse ato" (Taylor, 2013, p. 100). Tal estrutura é reencenada de tempos em tempos, conferindo autoridade por meio de raça, nacionalidade, gênero e crenças religiosas. Conforme Taylor descreveu, "como um sistema paradigmático de visibilidade, o roteiro também assegura invisibilidade" (Taylor, 2013, p. 92).

Os conceitos explorados acima se relacionam ao trabalho artístico de Ana Mendieta na medida em que ela utiliza seu próprio corpo como um meio para acessar e transmitir a memória cultural de suas origens cubanas. O uso da terra em suas obras está inevitavelmente ligado às reflexões sobre nação, pertencimento e exílio. O deslocamento da artista para os Estados Unidos, quando tinha apenas 12 anos, é parte fundamental da sua história e possui referências contínuas em suas criações, por meio da incorporação de práticas religiosas e culturais dos seus antepassados.

A série Siluetas, composta por mais de cem earth-body works produzidos entre 1973 e 1981, em lowa e no México (e conhecidos pelo público através das suas fotografias), exibe um diálogo constante do corpo feminino - o da própria artista - com a natureza. Mendieta age sobre a paisagem utilizando fogo, água, terra, sangue e vegetação para imprimir seus contornos, deixando que estes elementos também atuem sobre a sua obra. A longa sequência de trabalhos expõe fortes traços ritualísticos influenciados por seus conhecimentos sobre a Santeria (conjunto de práticas religiosas afro-cubanas) e as práticas ancestrais de populações indígenas pré-colombianas. 
Se, por um lado, não podemos separar a obra de Mendieta da influente presença da latinidade e do seu exílio, por outro, fixá-la numa identidade de artista latina se faz extremamente restritivo. Ao localizar a artista dentro de um roteiro hegemônico sobre exilados cubanos nos Estados Unidos, corre-se o risco de reduzir seu trabalho a um viés puramente pessoal e terapêutico - uma forma de superar as dores da sua expatriação traumática e reencontrar as raízes perdidas da sua cultura. Como amostras dessa banalização, Jane Blocker destaca as críticas feitas por Christine Poggi e John Perreault:

seus sentimentos de perda e desenraizamento foram as fontes de sua série Siluetas em andamento. [Mendieta] usa seu trabalho como um meio de estabelecer um "sentido do ser", de curar a "ferida" da separação. (...) Percebendo-se como exilada, Mendieta usou sua arte para curar a si mesma assim provocando e, talvez, curando outros. (Perreault \& Poggi, 1988 citados em Blocker, 1999, p. 77)

A própria artista referia-se constantemente a si mesma nos termos do seu exílio, conforme declarou em uma entrevista: "Eu faço esculturas na paisagem. Porque eu não tenho pátria, sinto uma necessidade de me juntar com a terra, de voltar ao seu ventre" (Mendieta citada em Blocker, 1999, p. 77). Contudo, para além de um sentido místico e curativo, seus trabalhos atingem profundas significações políticas, pois ao performatizar sua liminaridade - nacional, étnica, cultural -, Mendieta traz para a visibilidade, ao mesmo tempo em que questiona, a rigidez de uma identidade moldada aos povos latino-americanos. Buscando suas raízes na terra - e não na pátria - ela reivindica, usando as palavras de Blocker, "uma identidade em qualquer lugar" (Blocker, 1999, p. 78).

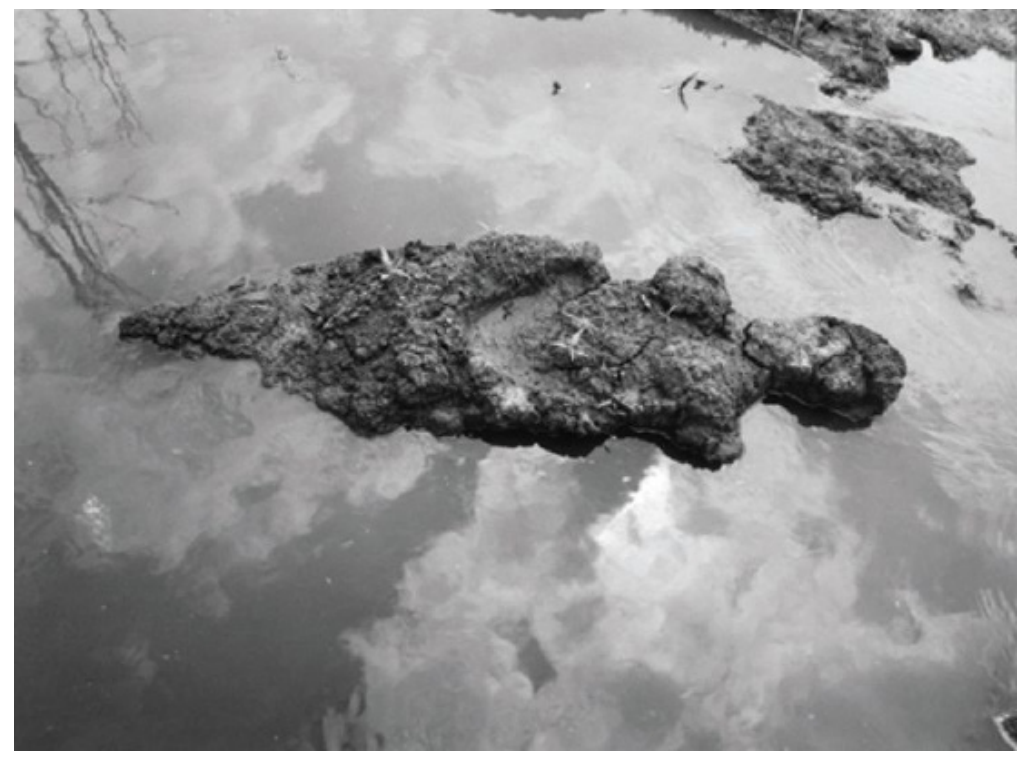

Figura 1: Isla, Série Silueta, Ana Mendieta, 1981 Fonte: Galerie Lelong

No earth work intitulado Isla (1981), Mendieta esculpiu a forma de um corpo feminino na margem de um riacho em lowa (Figura 1). Com seus contornos bem definidos 
e cercados por água, a imagem criada pela artista, bem como o título que lhe foi dado, sugere uma unidade territorial que nos remete à ilha de Cuba. Essa figura, no entanto, está entre dois lugares, ou "entre duas culturas", como a própria Ana declarou sobre si (Mendieta citada em Brett, 2004, p. 24). Ela é estranha àquela paisagem. Porém, devido ao seu caráter efêmero, logo irá se dissolver e integrar aos demais elementos do entorno. "É um mapa de Cuba feito na lama de lowa e como resultado é nem aqui nem lá; é um corpo em exílio" (Blocker, 1999, p. 80).

Para Jane Bloker, os significados de nação e exílio trabalhados por Mendieta são produzidos através das suas narrativas e performances. A ideia de nação não está atrelada a um espaço geográfico, mas sim à ligação emocional e ao sentimento de comunhão entre seus membros. Dessa forma, nação e exílio não podem ser pensados em termos binários e opositivos. Essa oposição é, segundo Blocker, o que "hegemonicamente preserva uma concebida pureza da nação definindo-a contra uma categoria percebida como sendo mais complexa e instável" (Blocker, 1999, p. 75). As obras de Mendieta, portanto, subvertem as oposições traçadas pelos roteiros de descobrimento (nós e o outro, nação e exílio, aqui e lá, político e pessoal) através da incorporação de práticas reiteradas. Deslocam da invisibilidade para a visibilidade - das bordas ao centro de sua atuação artística - memórias, ritos e comportamentos sociais historicamente marginalizados.

\section{MENDIETA E O SUJEITO FEMININO}

"No momento em que as mulheres usam o seu próprio corpo na arte, estão usando na verdade o seu próprio ser, fator psicológico da maior relevância, pois assim convertem o seu rosto e o seu corpo de objeto a sujeito" (Lippard, 1985, p. 190). Esta afirmação, feita por Lucy Lippard, diz respeito a um dos aspectos mais importantes da obra de Ana Mendieta: o uso do corpo como material e agente político na sua arte.

Seu trabalho criativo começou a florescer na década de 70 , em meio às fortes influências da arte conceitual estabelecida na década anterior e das proeminentes discussões do movimento feminista, com o qual a artista teve um grande envolvimento. A arte feminista daquela época era intensamente engajada na luta pela liberação feminina e nas reivindicações pela presença das mulheres nas instituições artísticas - espaços até então dominados por artistas brancos, do sexo masculino. As questões de representação e identidade que permeavam tais reivindicações causaram divergências dentro do próprio movimento, no que se refere aos debates em torno de uma essencialidade própria à categoria das mulheres.

Judith Butler aponta para as limitações de uma política de identidade que posicione as mulheres como o sujeito do feminismo. Para a autora, o termo mulheres torna-se problemático ao presumir uma categoria universal e estável, em nome da qual se busca a representação. Apenas pode reivindicar o reconhecimento no interior de um sistema de poder aquele que é produzido como um sujeito, de acordo com as normas deste mesmo sistema. Neste sentido, ser reconhecido é também ser definido dentro de uma estrutura regulatória e opressiva. Assim, nas palavras de Butler: 
não basta inquirir como as mulheres podem se fazer representar mais plenamente na linguagem e na política. A crítica feminista também deve compreender como a categoria das mulheres, o sujeito do feminismo, é produzida e reprimida pelas mesmas estruturas de poder por intermédio das quais busca-se a emancipação. (Butler, 2003, p. 19)

A teórica americana defende que as distinções entre sexo e gênero - bem como as funções sociais atribuídas a suas categorias - são profundamente marcadas por práticas discursivas. Para ela, os discursos em torno da naturalidade do sexo funcionam como uma forma de resguardar sua estabilidade interna a serviço de interesses sócio-políticos. O sexo é, antes de tudo, uma norma, uma dinâmica regulatória que se materializa de maneira impositiva, ou seja, uma prática "cuja força reguladora se manifesta como uma espécie de poder produtivo, o poder de produzir - demarcar, circunscrever, diferenciar - os corpos que controla" (Butler, 2002, p. 18). Do mesmo modo, a interpretação do gênero como um construto social pode produzir um efeito naturalizante que limita as suas possibilidades dentro de uma lógica dual ou, nas palavras da autora, "nos termos de um discurso cultural hegemônico, baseado em estruturas binárias que se apresentam como a linguagem da racionalidade universal" (Butler, 2003, p. 28).

Além disso, Butler afirma que as distinções de gênero estão atreladas de forma irremediável a outras categorias de identidade - racial, classista, étnica - igualmente construídas por meio do discurso. Segundo a autora, é "impossível separar a noção de gênero das interseções políticas e culturais em que invariavelmente ela é produzida e mantida" (Butler, 2003, p. 20). No mesmo sentido, Diane Taylor destaca a impossibilidade de isolar a memória cultural, raça e gênero, visto que as questões identitárias agem sobre a maneira com a qual os corpos participam do - e são produzidos pelo - sistema de transmissão de conhecimento e memória (Taylor, 1999). Tais questões mostram-se extremamente relevantes ao se analisar o corpo feminino e latino na produção artística de Mendieta.

O corpo, porém, não se limita inteiramente à lógica normativa que se sobrepõe a ele. Há sempre uma potência de desconstrução da ordem compulsória, que Butler problematiza ao articular a noção de performatividade de gênero. Na medida em que compreendemos as categorias de gênero em sua performatividade, isto é, como a reiteração de um conjunto de normas que adquire a condição de ato no presente e produz efeitos sobre a materialização do sexo (Butler, 2002), passamos a considerar que as diferenças sexuais, a construção simbólica - e até mesmo material - dos corpos podem ser reconfiguradas, subvertendo assim as posições estabelecidas de sexo e gênero. Esta subversão não diz respeito apenas ao cruzamento das fronteiras determinadas pela distinção binária homem-mulher, mas também à ruptura dos padrões impostos dentro de uma mesma categoria de sexo/gênero.

A inscrição performativa dos corpos femininos na arte foi inúmeras vezes classificada como narcisista. "Porque as mulheres são consideradas objetos sexuais", descreve Lippard, "é dado como certo que qualquer mulher que apresente seu corpo nu em público está fazendo apenas porque ela acha que é bonita" (Lippard citada em Blocker, 1999, p. 12). As performances de Mendieta foram definidas pela crítica ora como o símbolo de 
uma essência feminina dócil, vinculada à natureza intocada, ora como "um ser erótico (o mito do latino caliente), agressivo e de alguma forma ligado à perversão" (Mendieta citada em Brett, 2004, p. 24).

No entanto, o trabalho da artista desafia as definições essencialistas de mulher, pois suas estratégias de representação produzem significações para o corpo feminino a partir do desaparecimento. Segundo Jane Blocker, Mendieta sabia que simplesmente adicionar os marginalizados aos discursos de poder nada faria para mudar tais discursos e que, de fato, fazê-lo muitas vezes trabalha para reforçá-los. O esforço de tornar-se visível pode legitimar os termos colonizadores da visibilidade (Blocker, 1999). Na mesma direção Laura Mulvey, citada por María Ruido, afirma que:

em um mundo ordenado pela desigualdade sexual, o prazer de olhar encontra-se dividido entre masculino/ativo e feminino/passivo. O olhar masculino determinante projeta suas fantasias sobre a figura feminina, que se organiza de acordo com aquele. Em seu tradicional papel exibicionista, as mulheres são, ao mesmo tempo, vistas e exibidas. (Mulvey, 1975 citada em Ruido, 2002, p. 22)

Assim, o corpo na arte de Mendieta segue o sentido contrário à mera exibição de uma identidade. É um corpo que escorre, sangra, queima, explode, tem suas formas desfiguradas, sua feminilidade desnaturalizada. É um presente ausente que, através da aparição performática, denuncia a invisibilidade, a violência e o controle aos quais as muIheres são submetidas. Na série de fotografias Untitled (Glass on Body Imprints), de 1972, a artista pressiona uma placa de vidro sobre partes do seu corpo e rosto, distorcendo-os quase completamente (Figura 2). As feições grotescas adquiridas chamam atenção para a crueldade da construção normativa e estereotipada de um ideal de beleza feminina. O uso do corpo neste trabalho não é feito de maneira aleatória, pois, ao manipular sua própria carne, Mendieta converte-se em sujeito da representação e aposta na deformação como estratégia radical de luta contra a fetichização e a dominação do prazer visual masculino (Ruido, 2002).

Na performance Untitled (Facial Hair Transplant), também realizada em 1972, como finalização dos seus estudos na Escola de Arte da Universidade de lowa, Mendieta pediu a um amigo que cortasse a barba enquanto ela "transplantava" os pelos dele para a sua face, transformando-se conceitualmente em um homem. Através desta ação artística ela problematizou os mecanismos discursivos que perpassam a construção das identidades sexual e de gênero e parodiou os papéis sociais atribuídos com base nestas distinções. No relato sobre sua ação ela escreveu:

o pelo sempre me fascinou. A forma como cresce, onde cresce e a significação que as civilizações antigas lhe outorgavam. (...) Gosto da idéia de transferir pelo de uma pessoa a outra porque creio que me dá a força dessa pessoa. Depois de olhar-me no espelho, a barba se fez real. Não parecia um disfarce. Converteu-se em uma parte de mim mesma e não era, em absoluto, estranha à minha aparência. (Mendieta, 1972 citada em Ruido, 2002, p. 92) 

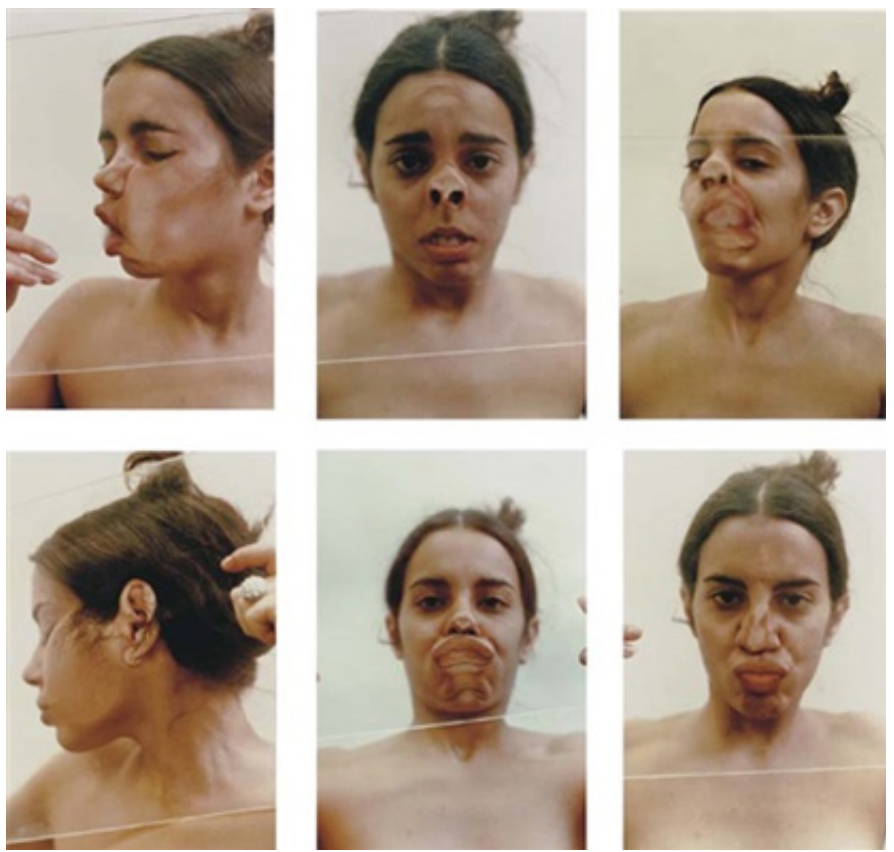

Figura 2: Untitled (Glass on Body Imprints), Ana Mendieta, 1972 Fonte: Galerie Lelong

Sobre o ato de se travestir, José Miguel Cortéz afirma que "quando um homem ou uma mulher se travestem (...) se abrem múltiplas possibilidades de reconfiguração do imaginário cultural; se questiona o significado de qualquer identidade masculina ou feminina" (Cortéz, 2004, p. 72). Ao utilizar o pelo em seu próprio rosto, como um símbolo de força atrelada à masculinidade, Mendieta brinca com o jogo binário das estruturas de sexo-gênero e cria para si uma aparência móvel, que subverte e passeia por estas identidades.

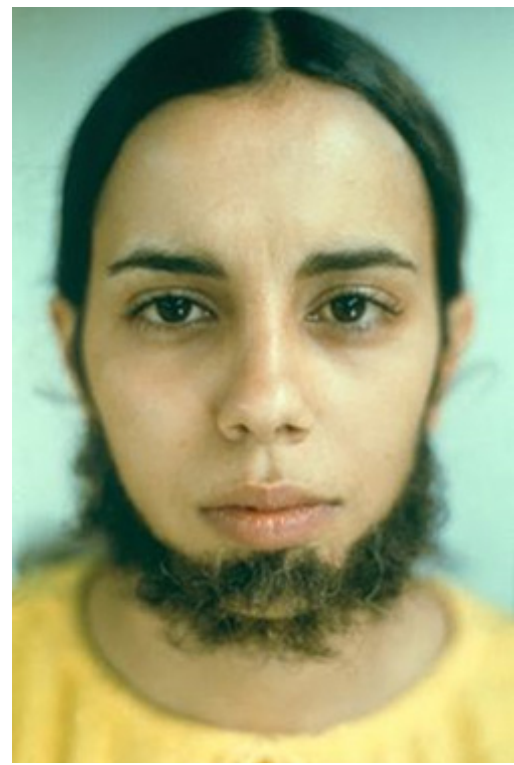

Figura 3: Untitled (Facial Hair Transplant), Ana Mendieta, 1972 Fonte: Galerie Lelong 
Mendieta afirma a sua atuação política por meio da criação estética ao rejeitar o sujeito feminino como uma categoria fixa que deve ser representada nos discursos de poder. Em vez disso, o "feminino" em suas obras aparece como um rastro, uma constante mutação e expansão dos limites impostos pelo gênero. Seu trabalho está em conformidade com a crítica feita por Butler à política de identidade como estrutura fundante do feminismo. Ao insistir no desaparecimento e na desconstrução do corpo como estratégia de representação, Mendieta impõe sua liminaridade e recusa os padrões colonizadores das definições de identidade.

\section{FotoperformanCE, PRESENTE E AUSENTE}

Já foi mencionado que as obras de Mendieta - assim como sua trajetória - foram frequentemente classificadas em termos de deslocamento, ausência e perda. Tais características, e seus paradoxais aspectos de afirmação e permanência, tiveram destaque não apenas nas temáticas exploradas pela artista, mas também nos meios criativos com os quais ela desenvolveu seus trabalhos.

A efemeridade da performance ao vivo, com sua condição ontológica de desaparecimento, é desafiada a partir da documentação feita com a câmera fotográfica. Mendieta deixou diversas fotografias (e também vídeos) das suas performances. Ela realizava seus trabalhos no aqui e agora do presente, porém, visando o registro para um tempo futuro. Este fator pode ser articulado aos conceitos de arquivo e repertório, desenvolvidos por Diane Taylor.

Para a autora, o arquivo refere-se aos "materiais supostamente duradouros", como documentos, textos, registros de áudio, fotografias e vídeos, que ultrapassam as barreiras temporais e espaciais. Já o repertório "é visto como efêmero, de práticas e conhecimentos incorporados" (Taylor, 1999, p. 48), como performances, rituais, linguagem, gestos. Por ser efêmero e mutável, o repertório requer presença física e frequentemente é tido como não reproduzível. Conforme a afirmação de Taylor:

a performance "ao vivo" nunca pode ser captada ou transmitida por meio do arquivo. Um vídeo de uma performance não é uma performance, embora frequentemente acabe por substituir a performance como uma coisa em si (...). A memória incorporada está ao vivo e excede a capacidade do arquivo de captá-la. Porém, isso não significa que a performance - como comportamento ritualizado, formalizado ou reiterativo - desaparece. (Taylor, 1999, p. 51)

Peggy Phelan assume uma postura bastante radical ao colocar o desaparecimento como a condição própria de existência da performance - a sua argumentação se refere especialmente às performance artísticas. O texto de Phelan estabelece características ontológicas segundo as quais a performance sobrevive apenas no presente, "não pode ser salva, registrada, documentada, ou de outra forma participar da circulação de representações de representações" (Phelan, 1993, p. 146). 
$\mathrm{Na}$ contramão das ontologias da performance que caracterizam o ao vivo e o midiatizado - o repertório e o arquivo - como formas opositivas, Philip Auslander problematiza os deslocamentos teórico-práticos da performance ao vivo dentro da cultura da midiatização. Ele aponta mudanças paradigmáticas (a crescente inserção de telas, aparelhos fotográficos e de vídeo nos acontecimentos ao vivo ou a própria apresentação de eventos tecnologicamente mediados como sendo ao vivo), reformulando pressupostos como presença física e propondo, para essa lógica, um sentido de vivacidade (liveness).

Como pano de fundo para sua argumentação, Auslander traz a relação entre o teatro e o surgimento da televisão. As primeiras transmissões de TV abraçaram os moldes do fazer teatral e eram feitas apenas ao vivo. Apesar de o meio não ter mais essa característica, a vivacidade ainda faz parte da linguagem televisiva, com suas pretensas propriedades de imediatismo, proximidade e veracidade. Porém, dentro do ambiente de midiatização, há uma subversão dos papéis e o midiatizado é que passa a servir de modelo para as performances ao vivo. "Dentro da nossa cultura midiatizada", o autor comenta, "qualquer distinção que possamos supor que haja entre os eventos ao vivo e os midiatizados está entrando em colapso porque eventos ao vivo estão se tornando mais e mais idênticos aos midiatizados" (Auslander, 2008, p. 32). O ao vivo, portanto, torna-se parte - tanto técnica quanto esteticamente - da economia da reprodução.

Mendieta desenvolveu a maior parte de suas performances sem a presença do público, com o intuito exclusivo de documentá-las. A experiência que a maior parte das pessoas tem de suas obras se dá graças à mediação pela fotografia. O espaço do documento, então, torna-se o único espaço no qual a performance acontece (Auslander, 2006). O dispositivo fotográfico confere vivacidade à ação artística e atualiza no presente os significados produzidos pela ausentificação do corpo performático.

A capacidade de permanência e reprodutibilidade da fotografia de performance também possui um caráter político, pois o arquivo está inevitavelmente ligado ao estabelecimento dos discursos de poder. Diane Taylor indaga: "de quem são as memórias, tradições e reivindicações à história que desaparecem se falta às práticas performáticas o poder de permanência para transmitir conhecimento vital?" (Taylor, 1999, p. 30).

Ao fazer a transição da representação para a reprodução, do repertório para o arquivo, Mendieta não apenas dota suas obras de um poder econômico de circulação (fotografias de performance tornam-se objetos negociáveis no mercado da arte), mas, sobretudo, confere a elas um maior impacto político. Assim a presença da fotografia não invalida a existência da performance, mas ultrapassa a sua visão ontológica, conferindo potência política ao garantir a sua permanência ao longo do tempo, ampliando sua audiência - através das galerias, museus, livros, catálogos e outros espaços - e possibilitando novas significações a partir da linguagem expressiva própria do meio fotográfico.

\section{Conclusão}

Conforme argumentamos, o trabalho da artista Ana Mendieta não apenas escapa às estruturas fixas de gênero, etnicidade e linguagem artística, como rompe completamente 
com qualquer tentativa de categorização nesses sentidos. Em seu breve período de expressão criativa, Ana desenvolveu cerca de 200 obras envolvendo performances ao vivo, além de fotografias e vídeos dos seus earth-body works.

Suas temáticas transitaram pela busca de um retorno à terra e às práticas de culturas ancestrais (motivada pelo seu exílio), pela denúncia de violências praticadas contra as mulheres e o questionamento da diferenciação social atribuída aos gêneros masculino e feminino. Em grande parte dessas obras, Mendieta recorreu ao desaparecimento e à desfiguração do corpo como forma de representação em performances que transformam fatos pessoais da artista em arte com profundas significações políticas.

Através da ação corporal em meio à natureza, Mendieta pôde tornar visível uma série de histórias, memórias e comportamentos sistematicamente silenciados pelas estruturas de poder. O uso da fotografia como registro e único local de sobrevivência da performance potencializa a força de sua atuação e a resistência em se classificar nas oposições binárias de nação/exílio, homem/mulher, efêmero/perpétuo.

Diante do exposto, podemos, então, considerar que repetir a pergunta feita pelas manifestantes em frente ao museu Guggenheim - “Onde está Ana Mendieta?" - significa reconhecer que essa importante artista não se deixou fixar em lugar algum. Mendieta foi uma artista múltipla e afirmou sua presença no mundo da arte e nas demais relações de poder questionando e expandindo os limites impostos pela rigidez no estabelecimento das categorias de identidade.

\section{REFERÊNCIAS BIBLIOGRÁFICAS}

Auslander, P. (2006). The Performativity of Performance Documentation. PAJ: Performing Arts Journal, 28(3), 1-10. doi: 10.1162/pajj.2006.28.3.1

Auslander, P. (2008). Liveness: Performance in a Mediatized Culture. Londres: Routledge.

Blocker, J. (1999). Where is Ana Mendieta: Identity, Performativity, and Exile. Durham e Londres: Duke University Press.

Brett, G. (2004). Única Energia. In Mendieta, earth body: sculpture and performance, 1972-1985 (pp. 22-45). Washington: Hirshhorn Museum.

Butler, J. (2002). Cuerpos que importan: sobre los limites materiales y discursivos del "sexo". Buenos Aires, Barcelona, Mexico: Paidós.

Butler, J. (2003). Problemas de Gênero: Feminismo e subversão da identidade. Rio de Janeiro: Civilização Brasileira.

Cortés, J. M. (2004). Acerca de La Construcción social del sexo e el género. In D. Perez (Ed.), La Certeza Vulnerable: cuerpo y fotografia em el siglo XXI (pp. 65-84). Barcelona: Editorial Gustavo Gili.

Lippard, L. (1985, novembro). Ana Mendieta 1948-1985 (obituary). Art in America Magazine, p.190.

Phelan, P. (1993). Unmarked: Politics of performance. Londres e Nova Iorque: Routledge.

Ruido, M. (2002). Ana Mendieta. Madrid: Nerea. 
Taylor, D. (2013). O Arquivo e o Repertório: Performance e Memória Cultural nas Américas. Belo Horizonte: Editora UFMG.

\section{FILMOGRAFIA}

Leeson L. H. (2010). Women Art Revolution. [Documentário no formato: 35mm e digital]. Londres: Hotwire Productions. Retirado de http://womenartrevolution.com

\section{NOTA BIOGRÁFICA}

Olga Wanderley é fotógrafa, pesquisadora e educadora da área da fotografia. Mestra em comunicação pela Universidade Federal de Pernambuco, Brasil, investiga as relações entre dispositivo fotográfico e performance artística.

E-mail: contato@olgawanderley.com

Universidade Federal de Pernambuco-UFPE, Rua PadreVilemain, 48, Campo Grande Recife-PE. CEP: 52.041-745, Brasil

* Submetido: 01-08-2017

* Aceite: 09-11-2017 